\title{
Missions: For Whom Does the Company Exist?
}

Abstract The unbundling of the corporate purpose in specific missions is a central question for management by missions (MBM). Missions, understood as the contributions that characterize the purpose, have been present in management life for close to half a century and today are one of the main management tools used by companies around the world. In this chapter, we discuss the relationship between purpose and missions. More specifically, we show how management by missions nurtures the development of purpose in three fundamental dimensions: content, credibility and sense of urgency.

Keywords Missions $\bullet$ Purpose $\bullet$ Stakeholder theory $\bullet$ Content $\bullet$ Credibility $\bullet$ Sense of urgency $\bullet$ Management by missions

Missions (or mission statements) have been used in the business world for decades. In 1943, R.W. Johnson wrote the Johnson \& Johnson (J\&J) credo, which lives on today. Forty years later, Jim Burke, the company's

The sponsors are: DPMC Foundation \& Chair in Management by Missions and Corporate Purpose (UIC) 
CEO, said he spent about $40 \%$ of his time promoting these principles among members of the organization. This credo, which reflects the company's commitment to serve its customers, employees, managers, members of its community and shareholders, is still valid. The latest version, updated in 2018 by current J\&J CEO Alex Gorsky, reflects the company's commitment to maintaining what it considers the key to business success: "Our credo has been a guiding light for our entire organization for the past 75 years. Through periods of immense change, it clearly conveyed a set of values that influenced not only what we needed to achieve, but also the actions we needed to take to reach those achievements."1

Tom Watson, son of the founder of IBM, did something similar in 1962, when he wrote the company's Basic Beliefs. When Louis V. Gerstner took over as CEO in the 1990s, these principles_-respect for the individual, customer service and excellence-still exerted a powerful influence on the company's culture. Gerstner himself went to great lengths to update Watson's Basic Beliefs and adapt them to the company's new situation and environment: "Perhaps the most important legacy of his leadership can be summed up in just three words: IBM means service." ${ }^{2}$

Gradually, over the second half of the twentieth century, the idea of the corporate missions - generally understood as a company's commitments to its stakeholders (customers, suppliers, shareholders, etc. ${ }^{3}$ - took root in companies, especially in North America and parts of Europe. A study carried out by Bain \& Co. and The Planning Forum in 1994 shows how important the missions had become by the mid-1990s. In interviews with more than 500 managers, the researchers analyzed 25 different management tools, including performance-related pay, workplace climate surveys, total quality, reengineering, customer satisfaction surveys and so on. Based on its findings, the study highlighted corporate missions as the most highly valued management tool, being used by $90 \%$ of companies. ${ }^{4}$

\footnotetext{
${ }^{1}$ See https://www.jnj.com/latest-news/johnson-johnson-ceo-alex-gorsky-reflects-on-the-power-ofthe-companys-credo. [Referenced: 11/9/2020]

${ }^{2}$ See https:/www.ibm.com/ibm/history/exhibits/vintage/vintage_4506VV2063.html. [Referenced: 11/9/2020]

${ }^{3}$ B.R. Bartkus and M. Glassman, "Do Firms Practice What They Preach?” art. cit., pp. 207-216.

${ }^{4}$ P. Jones and L. Kahaner, Say it \& Live it: The 50 Corporate Mission Statements That Hit the Mark, Doubleday, New York, 1995.
} 
Today, the vast majority of Fortune 500 companies, and practically all those ranking among the 100 Best Companies to Work For, have some kind of mission statement for their stakeholders. In summary, missions have been a fact of management life for close to half a century and today is one of the main management tools used by companies around the world.

\section{Purpose and Missions}

Since its inception, the word "mission" has had different interpretations and emphases in academic circles and in business. ${ }^{5}$ Sometimes, there has been confusion between the mission and other things such as vision, strategic objectives, corporate philosophy, corporate principles and so on. These days, the most common confusion is probably related to the terms "mission" and "purpose," which many view as the same thing. Indeed, there are quite a few companies and gurus of management that use these two words interchangeably, or use the word "mission" in reference to purpose.

This is the case of Microsoft, for example, which has stated: "Our mission is to empower every person and every organization on the planet to achieve more." Or that of Alibaba: "Our mission is to make it easy to do business anywhere." In reality, these statements correspond to what we defined earlier as purpose: what companies are for. While the purpose reflects what the company brings to the world, the missions reflect who the beneficiaries of that purpose are and how the company wants to impact their lives. Specifically, we can define missions as contributions that characterize the purpose of a person, group or organization.

Some supposed corporate "missions" do not fit that description. For example, missions described in positional terms: to be number one in a particular industry, or the industry benchmark or best in class, or one of the top 20 in a particular ranking and so on. These may be more or less

\footnotetext{
${ }^{5}$ I. Alegre, J. Berbegal-Mirabent, A. Guerrero and M. Mas-Machuca, "The Real Mission of the Mission Statement: A Systematic Review of the Literature," Journal of Management and Organization, vol. 24, no. 4, 2018, pp. 456-473.

${ }^{6}$ See https://www.microsoft.com/en-us/about. [Referenced: 11/9/2020]
} 
realistic objectives that may help a company fulfill its missions, but they are not the missions as such. The missions are the contribution that can give meaning to such goals: Why do we want to be number one in this industry? Why do we want to be in the top 20 in the rankings?

Missions are contributions; and a contribution is primarily a service, a specific way of solving real problems affecting individuals, groups or society as a whole. But not just any contribution is a mission. Missions are the contributions that characterize the purpose, that is, it gives a particular company, department, team or worker a reason for existence. For example, donating $1 \%$ of the company's profits to charity may be an important contribution; but it is very unlikely to be the company's defining contribution (though it may still be a valuable contribution that is consistent with the company's values and therefore worth maintaining).

\section{Characteristics of Missions: Content, Credibility and Urgency}

Creating a sense of purpose in the company requires more than simply writing missions down on a piece of paper (or posting them on a website). The mission statement alone has no impact on people and thus no impact on the company either. As J\&J CEO Alex Gorsky recalled, missions are only helpful if they have an influence on the objectives to be achieved, and on the actions needed to achieve them. To better understand the real impact of missions on a company, we can focus on the three essential conditions of all missions: content, credibility and urgency. These three characteristics reinforce one another in building a sense of purpose, so if any one of them fails, the sense of purpose will suffer.

\section{Content}

The content of the missions is the scope of the contribution pursued by that missions. The missions' content may vary in breadth, depth and richness. Missions with broad, deep and rich content are more likely to motivate than narrow, superficial or poor content. For example, if the 
company's missions are to maximize profit for shareholders and nothing else, employees are unlikely to identify with them (unless they happen also to be shareholders). Thus, with missions containing low-level content, the sense of purpose dwindles (and may even disappear completely). That is one reason why most companies give their missions more content, so that it expresses their commitment to the various stakeholders (employees, customers, shareholders, local community, etc.).

\section{Credibility}

High-content missions can serve no useful purpose without credibility. In fact, that is the problem with many companies: they lack credibility. Credibility is a question of engagement, starting with the engagement of managers and continuing with the impact of that engagement on management systems. Credibility is hurt if, on the one hand, you have deeply rooted missions and values, but, on the other hand, you have a management system that evaluates and rewards people based on increasingly aggressive financial objectives, which sometimes even run counter to the missions. This inconsistency cannot be resolved (and is more likely to be exacerbated) by internal propaganda or Christmas speeches by the general manager about the importance of the missions. Missions are what the company and its managers do, not what they would like to do or what people think is more "politically correct." When we define a mission, we must make sure that we're not talking about something totally unrelated to the company's current situation. To gain credibility, leaders must be the first to set an example of engagement, and management systems must be truly aligned with those missions.

\section{Urgency}

If there is no urgency to achieve something, it is because there is no real sense of purpose. A team or organization that does not have urgent and demanding goals has succumbed to paternalism, understood as a disease of unity. Competent companies are never content with what they have 
achieved to date; their sense of purpose always demands more. Good leaders are demanding, and very good leaders are very demanding. But they are also realists. A manager who sets unattainable goals is not a good leader, but a despot, which is typical of mediocre talent. Making "realistic demands" requires a balance based on a thorough knowledge of the market, people's abilities and available technology.

Urgency is not the same as stress. In fact, they are entirely different. Urgency is a priority system designed for high performance. Take, for example, a hospital emergency system. Urgency leads to action, intense effort, focused decisions. Stress, by contrast, is caused by irrational external pressure which the subject cannot control. As such, stress leads to paralysis, incapacity for sustained effort and dispersion. A bad leader amplifies stress: when they get pressure from their bosses, instead of transforming it into urgency by establishing priorities with a sense of purpose, they produce an even greater level of stress in their subordinates, giving orders that diminish their creativity and motivation. Unlike stress, urgency comes from within, when something is doing or needs to be done; always out of personal conviction. A good leader is one who knows how to instill in his or her subordinates a healthy sense of urgency in service of the purpose.

\section{The Stakeholder Model}

As we mentioned in the previous section, in order to have a positive impact, missions need to have content, and a breadth of vision about the company's fundamental contributions. A contribution focused exclusively on profit maximization only benefits shareholders (few of whom work in the company and interact directly with customers). Moreover, profit maximization can have an undesired side effect: the minimization of all the other variables. In other words, in this model, customers and employees are simply means to the end: shareholder profit. This vision eventually takes its toll and negatively impacts both employees and customers.

To avoid this situation, companies have looked for models that enhance the content of their missions. The stakeholder model is one of the most 
widely used today. ${ }^{7}$ With this model, companies define the contributions that characterize their purpose through the impact they have on their key stakeholders: customers, shareholders, employees and so on. Next, we will review the stakeholders most called upon in corporate missions.

\section{Customers}

Of the 1300 company missions we have analyzed, few fail to mention the customer in one way or another. Nowadays, it is difficult to conceive of a content-rich statement of principles that does not include the company's contribution to customers as a key ingredient. The company's contribution to its customers may be expressed in various ways. Companies in vastly different industries may describe it in similar terms, while others in the same industry, even in the same business, may see it very differently.

\section{Shareholders}

Traditionally, companies' contribution to shareholders has been taken to consist of two things: payment of dividends and increases in the company's value. These two things are what today is known as value creation. Briefly, value creation consists of providing remuneration, in the form of dividends or capital gains, above the cost of capital. Many companies' mission statements use terms such as fair remuneration, return, profit, value or value creation. These concepts start to depart from a mere commitment to profit maximization.

Moreover, value creation is not necessarily companies' only contribution to their shareholders. Management transparency and good corporate governance are examples of missions that go beyond the purely financial dimension. Such things may be particularly important in the case of family businesses or cooperatives, in addition to financial results, which are of particular importance to shareholders.

\footnotetext{
${ }^{7}$ R.E. Freeman and D.L. Reed, "Stockholders and Stakeholders: A New Perspective on Corporate Governance," California Management Review, vol. 25, no. 3, 1983, pp. 88-106.
} 


\section{Employees}

There is a growing belief that companies have an obligation toward those who allow them to exist: employees. Richard Branson, the enormously successful entrepreneur who founded Virgin Records, Virgin Atlantic Airways and many other companies, has stated in numerous speeches that employees come first, customers second and shareholders third. ${ }^{8}$ Authors such as Pfeffer have demonstrated, with numbers and real-world examples, that the best strategy for any company is to "put people first." This motto is preached by many companies that have made contribution to people one of the main pillars of their missions.

These three stakeholders-customers, shareholders and employeesare what many authors describe as key stakeholders or "primary constituencies." 10 They are the base on which most company missions around the world are founded. Besides the primary constituencies, many missions mention other stakeholders, such as suppliers, the environment, competitors, society at large, the public authorities, political associations and so on.

In August 2019, 181 CEOs from American companies signed the "Corporate Purpose Statement," including Tim Cook (Apple), Jeff Bezos (Amazon), Ramón Laguarta (PepsiCo) and Mary Barra (General Motors). This statement describes the commitment to five stakeholders.

While each of our individual companies serves its own corporate purpose, we share a fundamental commitment to our stakeholders. We commit to:

\footnotetext{
${ }^{8}$ J. Pfeffer, The Human Equation: Building Profits by Putting People First, Harvard Business School Press, Boston, MA, 1998.

${ }^{9}$ Ibid.

${ }^{10}$ J.P. Kotter and J.L. Heskett, Corporate Culture and Performance, Simon and Schuster, New York, 2008.
} 
- Delivering value to our customers. We will further the tradition of American companies leading the way in meeting or exceeding customer expectations.

- Investing in our employees. This starts with compensating them fairly and providing important benefits. It also includes supporting them through training and education that help develop new skills for a rapidly changing world. We foster diversity and inclusion, dignity and respect.

- Dealing fairly and ethically with our suppliers. We are dedicated to serving as good partners to the other companies, large and small, that help us meet our missions.

- Supporting the communities in which we work. We respect the people in our communities and protect the environment by embracing sustainable practices across our businesses.

- Generating long-term value for shareholders, who provide the capital that allows companies to invest, grow and innovate. We are committed to transparency and effective engagement with shareholders.

Each of our stakeholders is essential. We commit to deliver value to all of them, for the future success of our companies, our communities and our country.

In our opinion, materializing the purpose through missions geared toward the different stakeholders is a practice that will continue to increase in organizations. The rationale is that the commitment to stakeholders enhances the content of the missions. However, content is not the only key to impactful missions. It also needs credibility and urgency. In today's ever-changing environment, agility is vital. And agility requires a sense of urgency when undertaking missions that are not only stated but also assimilated and embodied by the entire organization.

This raises some questions, such as How can we get managers and employees to be truly committed to the missions? How are companies changing their management systems to drive their missions with a real sense of urgency? These are questions we will address in the third part of this book. But first, we will look at the characteristics that define the values of a balanced culture. 


\section{Purpose and Missions That Make a Difference}

Purpose and missions work in unison to mutually reinforce one another. In fact, it is increasingly common to see purpose and missions presented together. Some companies see this practice as a way of giving more content to brand positioning or slogans, developing their purpose to better reflect the essence of the organization. This is the case of The Coca-Cola Company, for example, in the recent update (version 2.0) of its principles by CEO James Quincey, whose December 2019 letter to employees explained:

Since we first talked about the concept of Beverages for Life in 2017, we've collectively created more momentum and belief in our business and across our system. The concept helped galvanize our actions. It has guided our continued evolution as a total beverage company. That was version 1.0. And as a good number of people have noted, Beverages for Life had a fuzzy connection to the company's existing mission and vision, and it left the company's purpose unclear. Our objective now is to lay out a version 2.0-and to give context to each piece and their connections. Ultimately, it needs to be explainable in simple terms, but also understood at a depth of detail.

With this objective in mind, The Coca-Cola Company has restored the purpose of the company launched back in 1886-"Refresh the world and make a difference." And its statement includes not only the purpose but also its commitments to key stakeholders: ${ }^{11}$

- Invest in employees' personal growth and talent for today and the future. We'll create a vibrant culture and leaders who help bring out the best in each person. Empower our people, provide access to equal opportunities and become more inclusive. We'll continue our global focus on women and ethnicity in locally relevant ways. Our programs range from societal efforts to those inside the company. We will be as diverse as the consumers we serve, and we'll be a more inclusive business.

- Create value for customers big and small. We'll bring brands and programs that become key parts of our customers' growth agendas, delivered with best-in class execution. We'll engage them in joint efforts for a more sustainable future.

(continued)

\footnotetext{
${ }^{11}$ See https://www.coca-colacompany.com/content/dam/journey/us/en/our-company/purpose-andvision/james-quincey-letter-to-employees-coca-cola-company-purpose-dec-2019.pdf. [Referenced: $11 / 9 / 2020]$
} 


\section{(continued)}

- Support local communities to achieve more, including in times of need. We'll continue our decades-long legacy of supporting local communities, through our business and through The Coca-Cola Foundation.

- Deliver returns to shareowners. Our investors range from major institutions to millions of individuals. They invest their money in The Coca-Cola Company because they want it to grow. They believe in our vision for our future and want us to succeed. We're committed to giving them a return on their investment.

PepsiCo, its rival, has a similar statement of principles. It has divided its purpose statement, "creating more smiles with every sip and every bite," into five categories. This is what Indra K. Nooyi, the company's CEO from 2006 to 2018, calls performance with purpose: ${ }^{12}$

- Consumers: Creating joyful moments through our delicious and nourishing products and unique brand experiences.

- Customers: Being the best possible partner, driving game-changing innovation and delivering a level of growth unmatched in our industry.

- Associates and Communities: Creating meaningful opportunities to work, gain new skills and build successful careers, and a diverse and inclusive workplace.

- Planet: Conserving nature's precious resources and fostering a more sustainable planet for our children and grandchildren.

- Shareholders: Delivering sustainable top-tier total shareholder return (TSR) and embracing best-in-class corporate governance.

When looking at the purpose of these two competing companies, we can see that the purpose is a commitment that characterizes the company's identity, but is not necessarily determined by the product or service provided. These two companies offer parallel products, yet they have decided to contribute to society in very different ways. Choosing different purposes will produce divergent strategies, ultimately leading to specific actions, experiences and innovations.

\footnotetext{
${ }^{12}$ See https://www.pepsico.com/about/mission-and-vision.
} 
Open Access This chapter is licensed under the terms of the Creative Commons Attribution 4.0 International License (http://creativecommons.org/licenses/ by/4.0/), which permits use, sharing, adaptation, distribution and reproduction in any medium or format, as long as you give appropriate credit to the original author(s) and the source, provide a link to the Creative Commons licence and indicate if changes were made.

The images or other third party material in this chapter are included in the chapter's Creative Commons licence, unless indicated otherwise in a credit line to the material. If material is not included in the chapter's Creative Commons licence and your intended use is not permitted by statutory regulation or exceeds the permitted use, you will need to obtain permission directly from the copyright holder.
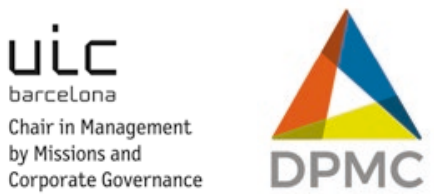